\title{
Método de utilização do programa Energyplus para verificação de desempenho térmico de ambientes com fachadas duplas
}

\author{
Method for using the Energyplus software to verify \\ thermal performance of enviroments with double skin \\ facade
}

\section{Sabrina Andrade Barbosa \\ Túlio Márcio de Salles Tibúrcio Joyce Correna Carlo Ítalo Bruno Baleeiro Guimarães}

\section{Resumo}

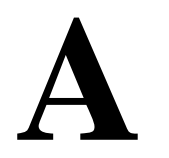

fachada dupla consiste de duas camadas, em geral envidraçadas, colocadas a certa distância, formando uma cavidade intermediária por onde o ar circula. Essas camadas abrangem fenômenos físicos complexos, como a ventilação por efeito chaminé e as trocas térmicas radiantes. Este trabalho apresenta um método de simulação com o programa EnergyPlus para análise do desempenho de um ambiente com fachada dupla. As camadas da fachada dupla estão submetidas às trocas radiantes e convectivas na cavidade intermediária devido ao efeito da ventilação provocado pela chaminé térmica. O método empregado considera a cavidade (entre camadas) como um microclima, cujas condições climáticas foram usadas para gerar um arquivo climático específico dessa zona. Esse arquivo foi posteriormente usado em outra simulação, que considerou apenas a camada interna da fachada, com foco na radiação solar. São apresentados dados que validam o processo de simulação, em vista das variáveis disponíveis pelo programa. Os resultados foram comparados a um caso-base sem fachada dupla. Os ganhos de calor pela fachada e as temperaturas operativas internas foram usados para verificação do desempenho térmico do ambiente com a fachada dupla. Esse processo fornece subsídios para análise de modelos mais complexos.

Palavras-chave: Fachada dupla. Chaminé térmica. Simulação computacional. EnergyPlus.

Sabrina Andrade Barbosa Universidade Federal de Viçosa Viçosa - MG - Brasil

Túlio Márcio de Salles Tibúrcio Universidade Federal de Viçosa Viçosa - MG - Brasil

Joyce Correna Carlo Universidade Federal de Viçosa Viçosa - MG - Brasil

Ítalo Bruno Baleeiro Guimarães Universidade Federal de Viçosa Viçosa - MG - Brasil

Recebido em 20/09/11

Aceito em 05/08/13

\section{Abstract}

Double skin façade consists of two layers, usually glass made, placed at a distance, forming a cavity that allows air circulation. These layers include complex physical phenomenon, such as the ventilation stack effect and thermal radiant exchanges. This paper presents a simulation method using the software EnergyPlus to analyse the performance of a double skin façade environment. The layers of the double skin façade were subjected to radiant exchanges and to the stack effect. The method considers the cavity (between layers) as a microclimate, where climatic conditions were used to generate a weather file of the specific conditions for that zone. The weather file was later used in another simulation, which considered only the inner layer of the façade, with focus on the solar radiation. The data presented validate the simulation process, given the variables available for the program. The results were compared to a base case without double skin facade. The heat gains in the façade and the internal operating temperatures were used to verify the performance of the environment with double skin facade. This procedure provides a basis to analyse more complex models.

Keywords: Double skin façade. Stack effect. Computational simulation. EnergyPlus. 


\section{Introdução}

A fachada dupla é composta, em geral, de uma camada de vidro colocada a certa distância da camada interior, e juntas formam uma cavidade, permitindo que o ar circule entre elas. A distância entre as duas camadas pode variar de alguns centímetros até a mais de um metro (GAVAN et al., 2008). Gratia e Herde (2007) argumentam que a principal razão arquitetônica para o uso da fachada dupla está relacionada à transparência, pois suas características permitem o contato próximo dos usuários com o entorno.

Segundo Manz e Frank (2005), edifícios com fachadas duplas envolvem temas complexos do ponto de vista de transferência de calor, necessitando de uma investigação cuidadosa logo nos primeiros estágios de concepção. A diversidade de formas de construção que podem alterar o comportamento térmico da fachada dupla e o grande número de parâmetros envolvidos leva à necessidade de criação de modelos e simulações. Segundo os mesmos autores, predizer e analisar o comportamento futuro de um edifício é mais eficiente e econômico que resolver problemas quando o edifício já está em uso. A simulação computacional é uma ferramenta capaz de prever, avaliar e verificar o desempenho do edifício (HENSEN, 2008). Hensen e Lamberts (2011) complementam que o desempenho da simulação computacional tem potencial para transmitir, direta ou indiretamente, benefícios às edificações e ao meio ambiente. Além disso, a simulação assume condições de contorno dinâmicas e normalmente baseadas em métodos numéricos que objetivam fornecer uma solução aproximada da realidade.

O desempenho de uma fachada dupla depende, em grande parte, do tipo de ventilação na cavidade e inclui os modos natural, representado pelo efeito chaminé e pressão do vento, mecânico ou misto. Resultados positivos em relação à economia energética e melhoria do desempenho térmico podem ser conseguidos com a exploração da ventilação natural, que se dá por meio de aberturas na camada externa, mesmo em edifícios de vários pavimentos (WONG; PRASAD; BEHNIA, 2008).

Ding, Hasemi e Yamada (2005) avaliaram o desempenho da ventilação natural em uma fachada dupla, por meio da construção de um protótipo físico no Japão e de simulação computacional. Eles explicam que o ar do espaço intermediário é aquecido devido à energia vinda da radiação solar. Com as aberturas das camadas da fachada dupla, o fluxo de ar é ativado pelo efeito chaminé. Em períodos mais quentes, o ar é extraído do ambiente pelo escoamento provocado pelo efeito da chaminé térmica, reduzindo o calor no ambiente. No inverno, as aberturas das camadas da fachada podem ser fechadas para evitar que o calor escape. Em estações mais amenas, o efeito chaminé que ocorre no espaço intermediário é normalmente usado como força motriz para promover a ventilação natural de todo o edifício. A ventilação é necessária para a troca higiênica do ar e tem estreita relação com as trocas de energia do edifício com o meio (EICKER et al., 2008).

Porém, a fachada dupla apresenta restrições para simulação de fluxo de ar através da cavidade, transferência de calor radiante, condutiva e convectiva através das áreas envidraçadas e na cavidade em programas de modelagem energética. Algumas dessas questões dependem da análise das simulações em CFD (Computational Fluid Dynamics - Dinâmica de Fluidos Computacional). Contudo, a maioria dos programas de CFD não fornece a incidência angular da radiação através das camadas da fachada, nem simula cargas de aquecimento e resfriamento do edifício, e também não é capaz de prever o consumo energético do conjunto. Esse tipo de simulação é realizado por programas de simulação energética, tais como o EnergyPlus e o Esp-r.

Srebric (2011) argumenta que o estado da arte atual sobre simulação de ventilação em ambientes construídos inclui modelos de rede de ventilação multizonas e dinâmica computacional dos fluidos (CFD). Versage (2009) explica que esses métodos apresentam limitações próprias. Com os modelos de rede de ventilação multizonas não é possível descrever a distribuição dos fluxos de ar no ambiente, no entanto é possível fazer simulações dinâmicas, calculando as taxas de fluxo de ar para todas as horas do ano. Os programas CFD descrevem o escoamento de ar dentro ou fora das edificações, fornecendo parâmetros detalhados para projetos como velocidades e temperaturas dos fluidos de forma mais rápida e confiável que os modelos de rede. Porém, eles fornecem resultados para pequenos intervalos de tempo. Assim, sua abordagem é mais detalhada quando comparada com os programas que usam modelos de rede de ventilação (SREBRIC, 2011). Vê-se, portanto, a necessidade de simular fenômenos e condições específicas relacionadas às fachadas duplas de acordo com recursos e algoritmos disponíveis em cada tipo de programa.

Este artigo apresenta os resultados da simulação de um modelo de um edifício com fachada dupla com foco nos ganhos térmicos relativos à transmissão da radiação solar através das superfícies transparentes da fachada. O procedimento justifica-se pela obtenção de resultados que 
consideram as mudanças nas distribuições de temperatura nas camadas da fachada em cada hora do ano completo, por meio da simulação dinâmica, o que não é possível obter com o uso do CFD, pois este é capaz de realizar simulações apenas para pequenos intervalos de tempo.

A fachada dupla é uma técnica desenvolvida para o clima frio. Porém, nos últimos anos, a aplicação da fachada dupla ganhou popularidade na prática de construção em países de clima quente, e cada vez mais aumenta o número de pesquisas relacionadas a seu uso para resfriamento. Neste trabalho, a simulação adotou o clima da cidade de Viçosa, MG, que é definido como tropical de altitude.

\section{Revisão de literatura: o programa Energyplus - potencialidades e limitações na modelagem de fachadas duplas}

O EnergyPlus é um programa de análise de energia e simulação de carga térmica de edificações. Ele apresenta recursos para simular o consumo de energia e as trocas térmicas resultantes dos efeitos radiantes e convectivos nos ambientes internos durante cada intervalo de tempo da simulação (CRAWLEY et al., 2004). O programa utiliza informações climáticas horárias do lugar, a descrição arquitetônica e construtiva do edifício, os padrões de uso e ocupação, a potência instalada em sistemas de iluminação, a carga dos equipamentos, as características do sistema de condicionamento de ar, entre outros.

Manz e Frank (2005) defendem a necessidade da divisão de modelagem e simulação das fachadas duplas em três níveis para uma simulação do desempenho térmico com confiança. No primeiro nível, os autores atentam para as reflexões, absorções e transmissões que ocorrem em cada face das diferentes camadas da fachada dupla. $\mathrm{O}$ segundo nível trata da dinâmica dos fluidos de ar na cavidade e pelo ambiente. O nível 3 aborda o comportamento térmico do conjunto e a condução do calor pelos materiais. Baldinelli (2009) complementa que a interação entre a radiação solar incidente e a energia fornecida ao ambiente interno, por meio da fachada dupla, se dá por ganho direto, em que a radiação solar é transferida através das superfícies transparentes, e por ganho indireto, que ocorre principalmente por convecção, através da entrada do ar da cavidade pela abertura.

O programa EnergyPlus possui um modo de modelagem que permite configurar a cavidade como uma chaminé térmica, simulando o efeito de ventilação que ocorre neste local devido ao aumento da temperatura do ar. O fluxo de ar originado da chaminé térmica é calculado pelas Equações 1 e 2.

$Q=C_{d} A_{o} \sqrt{2\left(\frac{T_{f o}-T_{r}}{T_{r}}\right) g L /\left(1+A_{r}\right)^{2}}$

$A_{r=} \frac{A_{o}}{A_{i}}$

Onde:

Q é o fluxo de ar que percorre a chaminé térmica $\left(\mathrm{m}^{3} / \mathrm{s}\right)$;

Cd é o coeficiente de descarga;

$\mathrm{A}_{\mathrm{o}}$ e $\mathrm{A}_{\mathrm{i}}$ são as áreas do corte transversal na entrada e saída do canal $\left(\mathrm{m}^{2}\right)$ respectivamente;

$\mathrm{T}_{\mathrm{fo}}$ é a temperatura do ar da atmosfera;

$\mathrm{T}_{\mathrm{r}}$ é a temperatura do ar no interior da cavidade (K);

g representa a aceleração da gravidade; e

Lé a altura total da chaminé térmica (m).

É importante esclarecer que o modelo de rede de ventilação do EnergyPlus permite trocas de massa entre zonas térmicas e entre uma zona térmica e o meio externo. Porém, o programa apresenta uma limitação: ele é incapaz de simular o efeito chaminé da cavidade simultaneamente às trocas de ar entre zonas e o meio externo. Quando o modelo de cálculo da chaminé térmica está ativado, só há troca de massa entre a cavidade e o ambiente interno nas modelagens de infiltração e nos modelos de ventilação unilateral. Assim, não há interação entre o fluxo de ar que percorre a cavidade e o ambiente interno. Na modelagem da chaminé térmica, só é contabilizada a contribuição térmica da chaminé, mas não as trocas de massa em si.

Para compensar essa limitação, em simulações de fachadas duplas, é possível integrar o modelo do EnergyPlus ao modelo de ventilação do CFD. Neste caso, o CFD usa como condições de contorno as temperaturas superficiais das paredes, a temperatura do ar e o fluxo de calor incidente na camada externa da fachada retirado do EnergyPlus (PAPPAS; ZHAI, 2008). Porém, o EnergyPlus é capaz de simular situações horárias para o ano completo, e o CFD limita-se a curtos intervalos de tempo.

Kim e Park (2011) modelaram a fachada dupla no programa EnergyPlus construindo três zonas empilhadas e interligadas por nós verticais em cada zona e nas aberturas horizontais entre elas. Com base no modelo de rede de ventilação do programa, foram definidas as temperaturas em cada nó de acordo com dados medidos em um 
experimento real. A modelagem só foi possível com o uso de dados experimentais, mediante o modelo de rede para simular o efeito da chaminé térmica.

\section{Método}

\section{Caracterização climática para simulação}

É importante ressaltar que a maioria dos casos de fachadas duplas encontrados na arquitetura localiza-se em países de clima frio. O uso de fachadas duplas é mais popular em edifícios de arranha-céus na Europa, e a maioria das pesquisas são feitas principalmente em países com condições de clima temperado (WONG; PRASAD; BEHNIA, 2008). Este trabalho usa os dados climáticos da cidade de Viçosa, MG $\left(20^{\circ} 77^{\prime} \mathrm{S} 42^{\circ}\right.$ $87^{\prime} \mathrm{O}$ ), que possui clima tropical de altitude.

Rodrigues et al. (2010) pesquisaram sobre o comportamento climático da cidade de Viçosa, MG, e definiram que o local apresenta períodos bem definidos com invernos secos e frios e verões quentes e úmidos. Segundo os autores, as temperaturas máximas médias registradas na estação entre 1968 e 2008 atingem seus valores mais elevados nos meses de fevereiro e março, sendo $29,3{ }^{\circ} \mathrm{C}$ e $28,6{ }^{\circ} \mathrm{C}$ respectivamente. As temperaturas mínimas médias registradas na estação para o mesmo período atingem seus menores valores nos meses de junho e julho, sendo respectivamente $11,1^{\circ} \mathrm{C}$ e $10,6^{\circ} \mathrm{C}$.

Segundo Guimarães e Carlo (2011), o relatório final emitido pelo programa Analysis Bio (desenvolvido pela LABEEE/UFSC) para as condições climáticas da cidade revelou desconforto em $61,6 \%$ das horas do ano, sendo $48,2 \%$ por frio e $13,4 \%$ por calor. Quanto à radiação solar, o local apresenta valores bem distribuídos entre os períodos da manhã e da tarde.

\section{Modelagem dos casos com e sem fachada dupla}

$\mathrm{Na}$ ausência de dados experimentais como no trabalho desenvolvido por Kim e Park (2011), foram desenvolvidos procedimentos para a modelagem de ambientes com fachada dupla utilizando-se o software EnergyPlus. O método proposto neste trabalho consiste na formulação de dois casos (casos 1 e 2), que compõem um modelo de um ambiente com fachada dupla cujo desempenho foi comparado a um caso-base (caso 3), conforme o Quadro 1.

Quadro 1 - Detalhes da simulação dos três casos executados no EnergyPlus

\begin{tabular}{|c|c|c|c|c|c|}
\hline Casos & Modelo & Avalia & $\begin{array}{l}\text { Dados de } \\
\text { entrada }\end{array}$ & $\begin{array}{c}\text { Dados de saída }^{1} \\
\text { para resultados } \\
\text { parciais e/ou finais }\end{array}$ & $\begin{array}{c}\text { Para } \\
\text { comparação } \\
\text { entre casos } 1 \text { e } \\
2\end{array}$ \\
\hline Caso 1 & $\begin{array}{c}\text { Com fachada } \\
\text { dupla }\end{array}$ & $\begin{array}{l}\text { Efeito chaminé } \\
\text { (convecção) e } \\
\text { trocas radiantes } \\
\text { e de massa da } \\
\text { cavidade e o } \\
\text { meio externo }\end{array}$ & $\begin{array}{l}\text { Arquivo } \\
\text { climático local } \\
\left(\mathrm{TMY}^{2} \text { de }\right. \\
\text { Viçosa, 2005- } \\
\text { 2010) }\end{array}$ & $\begin{array}{l}\text { Temperaturas de } \\
\text { bulbo seco, de bulbo } \\
\text { úmido e de ponto de } \\
\text { orvalho; radiações } \\
\text { direta e difusa: } \\
\text { microclima }\end{array}$ & $\begin{array}{l}\text { Temperatura } \\
\text { superficial da } \\
\text { face externa da } \\
\text { janela interna }\end{array}$ \\
\hline Caso 2 & $\begin{array}{c}\text { Sem fachada } \\
\text { dupla }\end{array}$ & $\begin{array}{c}\text { Trocas } \\
\text { radiantes do } \\
\text { microclima } \\
\text { com o meio } \\
\text { interno }\end{array}$ & $\begin{array}{l}\text { Arquivo } \\
\text { climático do } \\
\text { microclima }\end{array}$ & $\begin{array}{l}\text { Ganhos de calor e } \\
\text { temperatura } \\
\text { operativa do } \\
\text { ambiente interno }\end{array}$ & $\begin{array}{l}\text { Temperatura } \\
\text { superficial da } \\
\text { face externa da } \\
\text { janela interna }\end{array}$ \\
\hline Caso 3 & $\begin{array}{c}\text { Sem fachada } \\
\text { dupla }\end{array}$ & $\begin{array}{c}\text { Trocas } \\
\text { radiantes e de } \\
\text { massa do } \\
\text { ambiente } \\
\text { interno com o } \\
\text { meio externo }\end{array}$ & $\begin{array}{c}\text { Arquivo } \\
\text { climático local } \\
\text { (TMY de } \\
\text { Viçosa, 2005- } \\
\text { 2010) }\end{array}$ & $\begin{array}{l}\text { Ganhos de calor e } \\
\text { temperatura } \\
\text { operativa do } \\
\text { ambiente interno }\end{array}$ & - \\
\hline
\end{tabular}

\footnotetext{
${ }^{1}$ Dados de saída são dados horários fornecidos pelo programa após sua execução. Trata-se dos resultados não processados das condições do ambiente simulado ou dos padrões definidos pelo usuário.

${ }^{2}$ Arquivo climático TMY-Typical Meteorological Year (Ano Meteorológico Típico) apresenta dados horários de temperatura de bulbo seco, temperatura de bulbo úmido, umidade, pressão barométrica, direção e velocidade do vento, nebulosidade, radiação solar, entre outros dados.
}

124 Barbosa, S. A.; Tibúrcio, T. M. de S.; Carlo, J. C.; Guimarães, I. B. B. 
Primeiramente, foi necessária a definição e modelagem da tipologia de fachada dupla simulada, em que foram determinadas a geometria das zonas térmicas, os materiais empregados e as dimensões da zona da chaminé térmica, ou zona da cavidade. A etapa seguinte consistiu na simulação do caso 1 . O modelo apresenta uma fachada dupla com uma cavidade intermediária. Considerando as condições da cavidade como um microclima ao qual o ambiente interno está exposto, foi possível a obtenção das condições climáticas dessa cavidade.

Assim, um arquivo climático das condições específicas da cavidade foi criado e, posteriormente, usado na simulação do caso 2 . Esse arquivo climático foi gerado a partir das condições de temperaturas, umidade e radiação solar incidente na superfície da janela do ambiente do caso 1. O segundo modelo possui apenas a camada interna da fachada dupla, com sua janela. Para verificar a coerência dos casos 1 e 2, as temperaturas superficiais do vidro da janela do segundo modelo foram comparadas com as obtidas no caso 1 .

Para efeito comparativo, foi simulado também um caso-base (caso 3), com o mesmo arquivo climático usado no caso 1. Este caso 3 manteve os materiais do modelo do caso 1 , porém sem a camada externa da fachada dupla (Figura 1). O intervalo de tempo em que o programa faz uma simulação completa (time step) em todos os modelos foi de 15 min, e todos os casos incluem as trocas por condução.

Os materiais construtivos dos modelos foram obtidos do trabalho de Ordenes et al. (2003), em que caracterizaram os componentes construtivos nacionais. Segundo os autores, para o desenvolvimento de um componente equivalente a ser inserido na biblioteca do VisualDOE (interface do DOE2.12, que antecedeu o EnergyPlus), foi adotado um método de cálculo em que se variam as espessuras e densidades de massa aparente dos materiais, mantendo constantes a resistência térmica $(\mathrm{Rt})$ e a capacidade térmica $(\mathrm{Ct})$ entre as superfícies do componente. Todas as paredes foram modeladas com uma camada interna e outra externa de argamassa de emboço e tijolo cerâmico de 6 furos no centro, sendo as lajes de cobertura e piso do tipo mista de $12 \mathrm{~cm}$. O Quadro 2 apresenta as características dos sistemas construtivos utilizados.

\section{Definição do modelo do caso 1}

O modelo simulado possui três zonas térmicas, conforme apresentado na Figura 2:
(a) cavidade formada pela fachada dupla;
(b) ambiente interno; $\mathrm{e}$
(c) ambiente no pavimento inferior.

Figura 1 - Fluxograma do processo de simulação de um ambiente com fachada dupla

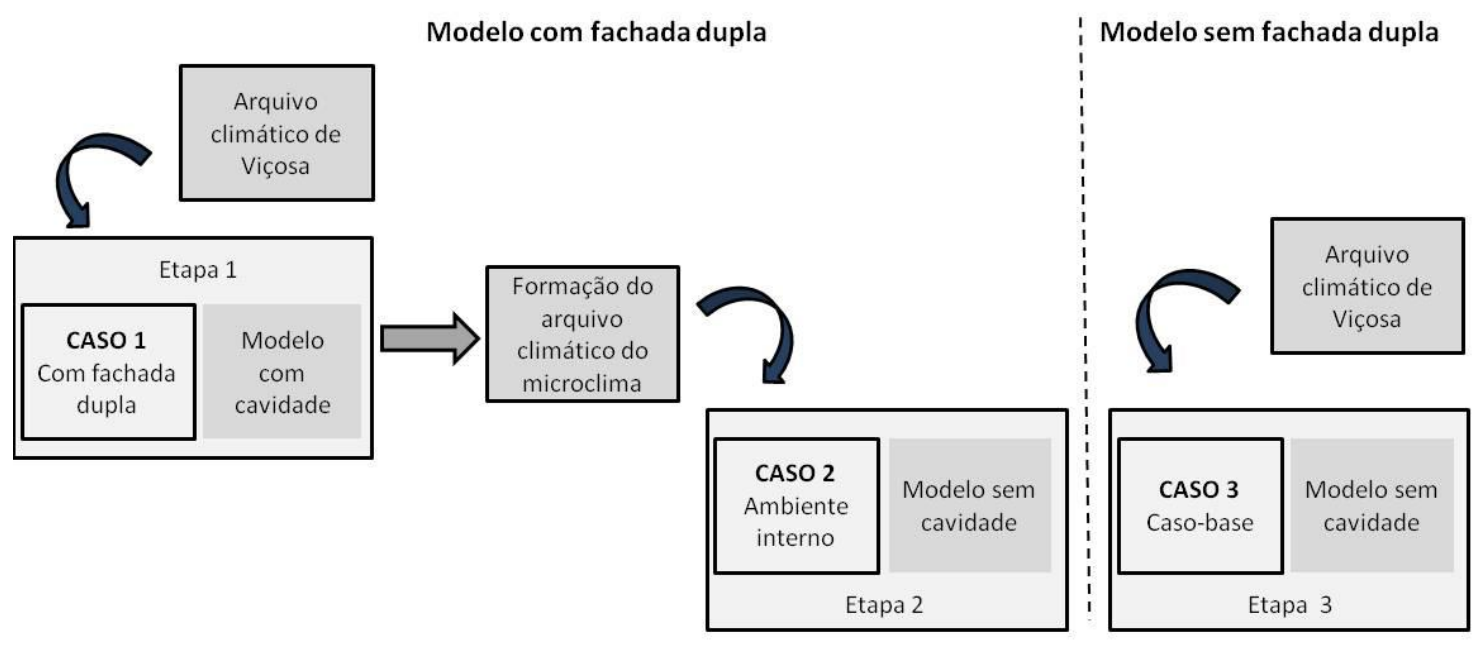

Quadro 2 - Propriedades térmicas dos sistemas construtivos utilizados no modelo

\begin{tabular}{c|c|c|c}
\hline Sistema & Espessura $(\mathbf{c m})$ & Capacidade térmica $\left(\mathbf{k J} /\left(\mathbf{m}^{2} . \mathbf{K}\right)\right.$ & $\begin{array}{c}\text { Resistência térmica } \\
\left(\mathbf{m}^{\mathbf{2}} \mathbf{K} / \mathbf{W}\right)\end{array}$ \\
\hline Paredes & 2,5 & 194,3 & 0,241 \\
Lajes & 12,0 & 12,0 & 0,090 \\
\hline
\end{tabular}




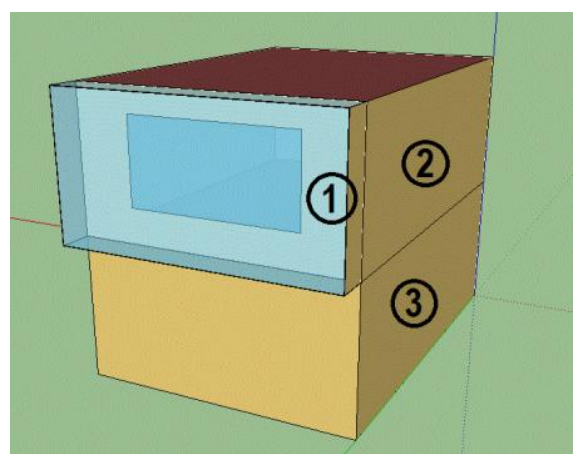

O modelo possui as aberturas horizontais na base e no topo da cavidade, com o padrão de abertura 24 h por dia, durante todos os dias do ano. O modelo não possui condicionamento de ar ou sistemas mecânicos. A fachada dupla está à frente de apenas um pavimento, pois a avaliação é feita somente para as trocas radiantes das camadas da fachada, excluindo a análise do fluxo de ar entre a cavidade e o ambiente interno. O Quadro 3 apresenta a descrição das características do modelo.

\section{Etapa 1: simulação do caso 1 para obtenção do microclima}

Esta etapa visou à criação do arquivo climático com dados do microclima da cavidade. Primeiramente foram determinados os dados necessários à formação do arquivo climático: temperatura de bulbo seco, temperatura de bulbo úmido, temperatura de ponto de orvalho, radiação direta normal e horizontal, radiação difusa normal e horizontal e radiação global.

A primeira etapa do processo usou o arquivo climático de Viçosa modificado, em que as direções e velocidades do vento foram zeradas, para criar uma situação teórica de calmaria no ano completo. Assim, isolou-se o efeito chaminé de outras trocas de energia e massa decorrentes dos efeitos do vento.

A simulação forneceu as condições térmicas da face interna da cavidade (janela interna, conforme a Figura 3), que separa esta zona do ambiente interno. Assim, foram obtidos dados horários da TBU (temperatura de bulbo úmido) da cavidade, da TBS (temperatura de bulbo seco) da camada de ar adjacente à janela e das radiações diretas incidentes na janela após passar pelo vidro da camada externa da fachada dupla. As TBS, TBU e radiação direta foram inseridas diretamente no arquivo climático que representa o microclima da cavidade.
Também foi necessário inserir a radiação global no arquivo climático, que é a soma da radiação direta e difusa, mas o programa não fornece diretamente a radiação difusa incidente na superfície da janela (Ids), mas apenas a quantidade de radiação difusa que foi absorvida por seu vidro (Ida). Assim, a radiação difusa incidente na fachada foi calculada por meio do valor obtido na simulação (Ida), corrigindo o valor fornecido pela absortância solar do vidro.

Porém, a energia radiante absorvida pelo vidro é função da metade da radiação difusa disponível na abóbada celeste, e um arquivo climático deve ser composto de $100 \%$ da radiação difusa disponível na abóbada celeste que incide no plano horizontal. Portanto, foi necessário extrair a radiação difusa incidente na superfície externa vertical da cavidade - que o programa fornece - para todas as horas do ano. De acordo com a apresentação da distribuição da radiação difusa na abóbada celeste por Duffie e Beckman (1991), esses valores foram multiplicados por 2, para corresponder à radiação difusa incidente em $100 \%$ da abóbada celeste, chamada Idec (radiação difusa horária da face externa calculada).

Os dados medidos para Viçosa registram as radiações de um céu real, enquanto a Idec representa um céu cuja metade norte é idêntica à metade sul. Os resultados foram comparados com a radiação difusa horizontal extraída diretamente como dado de saída do programa (Id). Nessa comparação, foram encontradas diferenças entre as Id e Idec. Em seguida, foi possível repetir internamente o processo realizado com a radiação difusa externa: Ids foi multiplicada por 2, para considerar a abóbada celeste completa, e finalmente corrigida pelas diferenças encontradas entre Idec e Id. A Figura 4 apresenta o processo para obtenção da radiação difusa incidente na face da janela interna. 
Quadro 3 - Características da modelagem do caso 1 no EnergyPlus

\begin{tabular}{|l|l|}
\hline Arquivo climático & Arquivo de Viçosa, MG (sem vento) \\
\hline Dimensões do modelo & Largura: $6,5 \mathrm{~m}$; Altura: $3,4 \mathrm{~m}$; Profundidade: $9,1 \mathrm{~m}$ \\
\hline Dimensões da cavidade & Largura: $0,80 \mathrm{~m}$; Altura: $3,4 \mathrm{~m}$ \\
\hline Orientação da fachada dupla & Norte \\
\hline Zonas & Três: ambiente-teste, ambiente inferior e cavidade \\
\hline Vidros & Incolor de $6 \mathrm{~mm}$ \\
\hline $\begin{array}{l}\text { Faces direita e esquerda da } \\
\text { cavidade, coberturas e pisos }\end{array}$ & Adiabáticas \\
\hline
\end{tabular}

Figura 3 - Corte esquemático (face em que os dados de saída foram obtidos)

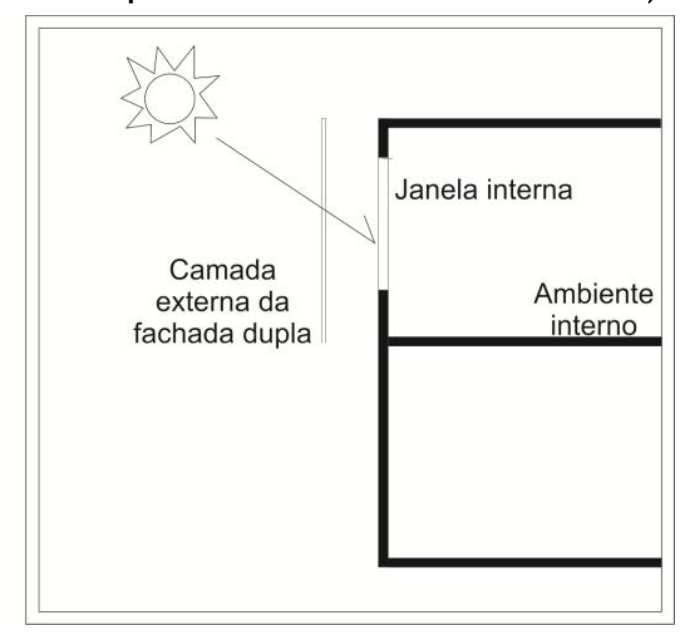

Figura 4 - Fluxograma do processo de correção da radiação difusa para arquivo climático do microclima
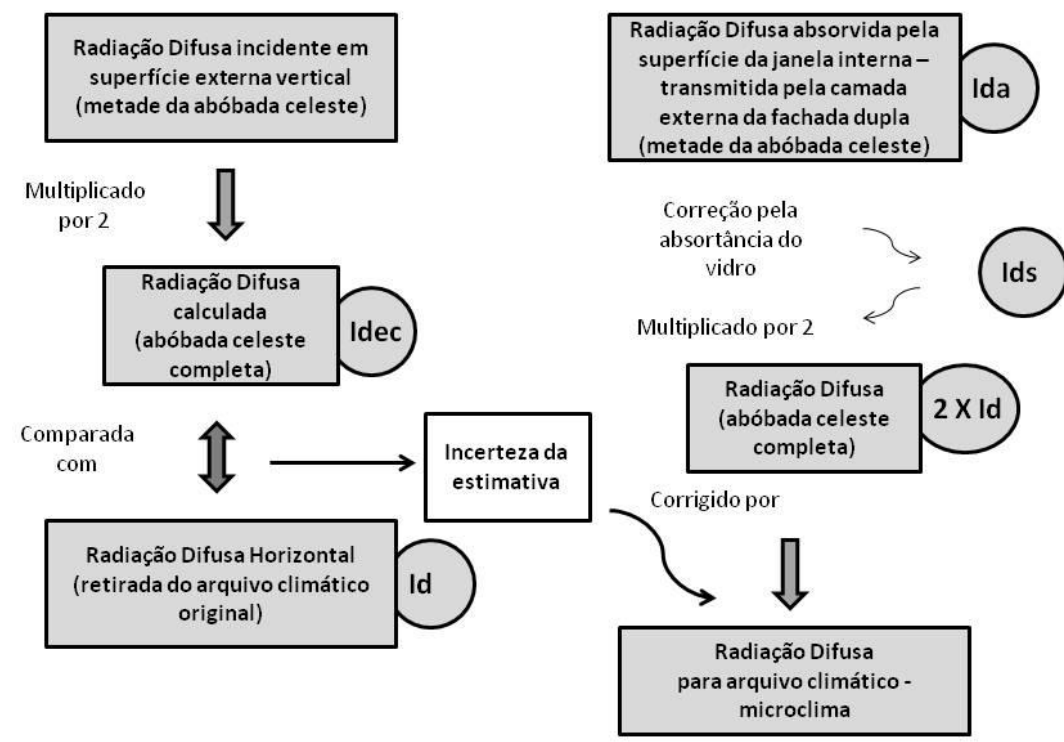

A radiação de onda longa irradiada pelo vidro da camada externa da fachada foi proporcionalmente somada às radiações direta e difusa no arquivo sendo, portanto, pouco relevante na análise dos resultados para este clima ${ }^{3}$.

climático do microclima. No entanto, os valores encontrados para a radiação de onda longa representam, em média, $1 \%$ da radiação global,

\footnotetext{
${ }^{3}$ Este resultado parcial indica que a radiação de onda longa é pouco relevante na prática, pois representa cerca de $1 \%$ da radiação global.
} 


\section{Etapa 2: simulação do ambiente interno com novo arquivo climático}

Esta etapa consistiu na simulação do caso 2, usando, porém, o arquivo climático desenvolvido na etapa anterior. $\mathrm{O}$ arquivo da cavidade possui a velocidade e a direção do vento zeradas, portanto as condições também são de calmaria. Dessa forma, evitou-se que o efeito do vento na simulação do caso 2 viesse a mascarar as condições do efeito chaminé do arquivo criado (microclima), já que nessa fase não há fisicamente a cavidade, mas apenas suas condições climáticas. Assim, o efeito chaminé foi isolado em relação ao vento local.

Para conferir as condições climáticas do microclima da cavidade no caso 1 com o clima externo no caso 2 , foi usada como comparação a temperatura superficial da janela interna, que deve ter valores próximos nas simulações dos casos $1 \mathrm{e}$ 2. Vale lembrar que, para essa variável, o programa não considera a sobreposição de folhas de vidro da janela aberta: as trocas radiantes são consideradas com janelas fechadas.

\section{Etapa3: simulação do caso-base (sem fachada dupla)}

Para a simulação do caso 3 (sem a fachada dupla), foi modelada a geometria do caso 2 com o arquivo climático da cidade de Viçosa, MG, o mesmo usado no caso 1. Os principais dados extraídos dessa simulação foram o ganho de calor na zona pela janela e a temperatura operativa do ar na zona interna, que foram comparados com os mesmos dados obtidos a partir da simulação do caso com fachada dupla (caso $1+$ caso 2). O Quadro 4 apresenta os dados obtidos pelo programa e as comparações feitas entre os casos 1, 2 e 3 .

\section{Análise dos resultados}

\section{Comparação das temperaturas superficiais da janela para os casos $1 \mathrm{e}$ \\ 2}

A Figura 5a apresenta a frequência de ocorrência dos intervalos de diferença das temperaturas superficiais da janela nos casos 1 e 2, e a Figura 5 b apresenta a frequência de ocorrência acumulada para os mesmos dados. As diferenças encontradas variaram até pouco mais que $4{ }^{\circ} \mathrm{C}$, no entanto esse evento ocorreu em apenas dois horários do ano completo, representando $0,02 \%$ do total. Aproximadamente $90 \%$ dos casos apresentaram diferenças de até $2{ }^{\circ} \mathrm{C}$.

\section{Quadro 4 - Resumo das comparações feitas entre os dados obtidos pelo programa}

\begin{tabular}{|c|c|c|}
\hline Dado comparado & Casos comparados & Finalidade \\
\hline $\begin{array}{c}\text { Temperatura superficial da } \\
\text { janela }\end{array}$ & Casos 1 e 2 & $\begin{array}{c}\text { Conferir as condições climáticas do } \\
\text { microclima da cavidade }\end{array}$ \\
\hline $\begin{array}{c}\text { Ganhos térmicos no } \\
\text { ambiente }\end{array}$ & Casos 2 e 3 & $\begin{array}{c}\text { Verificar a contribuição do ganho de calor } \\
\text { no ambiente pela fachada dupla }\end{array}$ \\
\hline $\begin{array}{c}\text { Temperatura operativa no } \\
\text { ambiente }\end{array}$ & Casos 2 e 3 & $\begin{array}{c}\text { Avaliar as diferenças no desempenho do } \\
\text { ambiente com e sem fachada dupla }\end{array}$ \\
\hline
\end{tabular}

Figura 5 - (a) Frequência de ocorrência e (b) frequência de ocorrência acumulada dos intervalos de diferenças entre as temperaturas superficiais das janelas dos casos 1 e 2

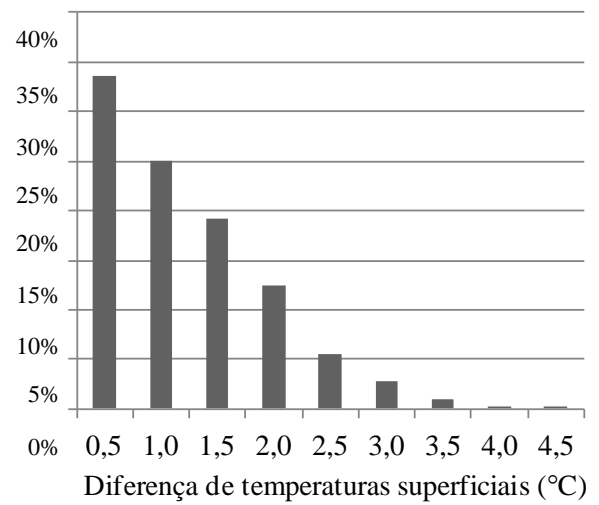

(a)

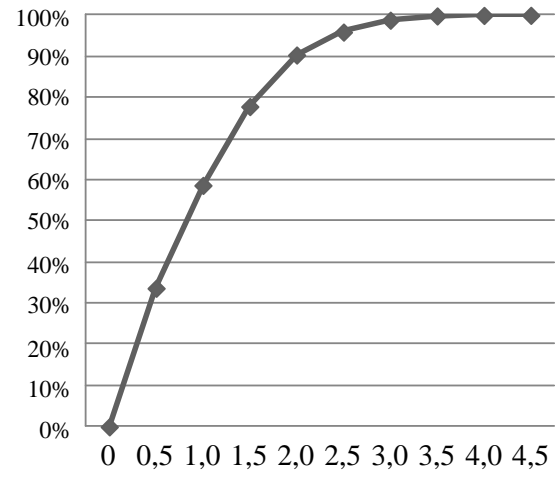

Diferença de temperaturas superficiais $\left({ }^{\circ} \mathrm{C}\right)$

(b)

128 Barbosa, S. A.; Tibúrcio, T. M. de S.; Carlo, J. C.; Guimarães, I. B. B. 
As temperaturas superficiais mínimas, médias e máximas externas da janela para os casos 1 e 2 são apresentadas na Figura 6a para os meses de verão (dezembro a março), e na Figura 6b, para os meses de inverno (junho a setembro). É possível observar que, no verão, as médias são semelhantes, mas os desvios padrão não o são, sendo maiores no caso 1 (3,92 no verão e 5,07 no inverno para o caso 1 , e 3,19 no verão e 4,71 no inverno no caso 2 ). O efeito convectivo da chaminé térmica existente no caso 1 pode ser responsável por essa diferença nos desvios padrão. Tal efeito é mais acentuado no inverno, quando as temperaturas superficiais tendem a ser mais baixas, como indicado por sua média $\left(21,3{ }^{\circ} \mathrm{C}\right.$ para o caso 1 e $22,9{ }^{\circ} \mathrm{C}$ para o caso 2). O caso 2 , portanto, apresenta temperaturas superficiais mais estáveis, que foram definidas apenas por seu microclima, sem a participação das trocas convectivas. Essa estabilidade também se refletiu nas temperaturas superficiais extremas, onde, embora as mínimas sejam semelhantes, as temperaturas superficiais máximas são menores no caso $2\left(38,6^{\circ} \mathrm{C}\right.$ para o caso 1 e $36,1^{\circ} \mathrm{C}$ para o caso 2 no verão, e $37,2^{\circ} \mathrm{C}$ para o caso 1 e $35,8^{\circ} \mathrm{C}$ para o caso 2 no inverno).

As diferenças apresentadas nas Figuras $6 a$ e $6 b$ indicaram as limitações do procedimento relativas às diferenças de temperatura nos dois casos.
Considerando o número de dados analisados $(8.760 \mathrm{~h})$, tem-se que na grande maioria dos momentos do ano há pequenas diferenças de temperatura entre os casos 1 e 2. Assim, os resultados obtidos a partir da comparação das temperaturas superficiais da janela nos dois modelos indicam que o método apresenta coerência aceitável, atestando a possibilidade de seu uso.

\section{Comparação entre o modelo com fachada dupla (caso $1+$ caso 2 ) e o caso-base (caso 3)}

Analisando-se as temperaturas de bulbo seco do ambiente externo de Viçosa e da cavidade, para o caso com fachada dupla, é possível afirmar que em $100 \%$ das horas do ano, o que inclui o período noturno no inverno, as temperaturas médias diárias do ar são maiores na cavidade. A Figura 7 apresenta as temperaturas de bulbo seco mínimas, médias e máximas das médias diárias ao longo do ano para o clima de Viçosa e para o microclima (cavidade). A diferença entre a máxima das médias diárias do ar da cavidade em relação ao meio externo foi de $4,8{ }^{\circ} \mathrm{C}$, e o valor mínimo entre as médias diárias foi $2,0^{\circ} \mathrm{C}$ menor para o ar externo. Já a média das temperaturas diárias possui diferença de $4,2^{\circ} \mathrm{C}$.

Figura 6 - Representação gráfica da análise estatística das temperaturas superficiais do vidro nos casos 1 e 2 para os meses de (a) verão (dezembro a março) e (b) inverno (junho a setembro)

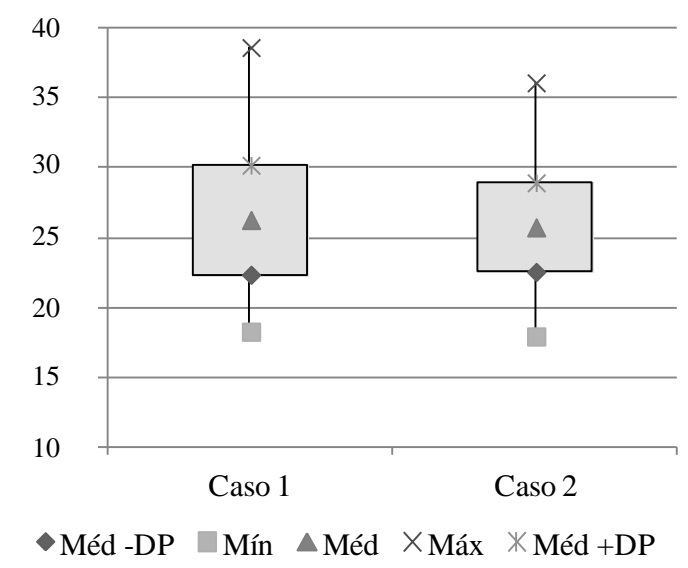

(a)

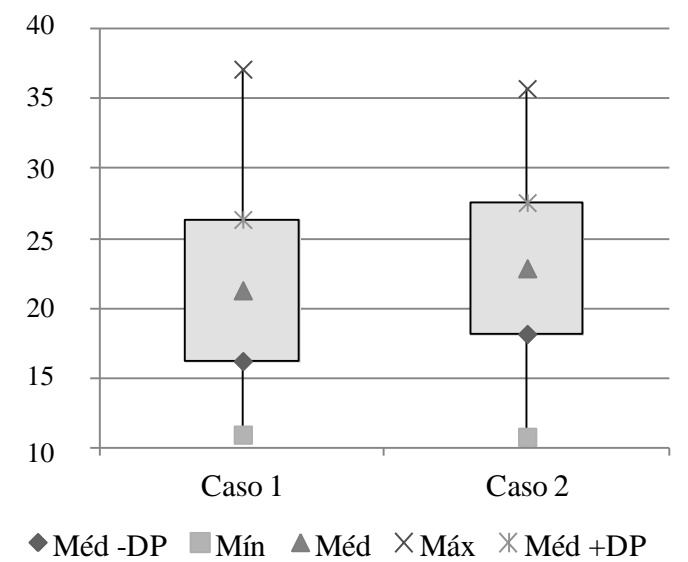

(b)

Nota: Méd-DP = média menos desvio padrão;

Mín = valor mínimo;

Méd = média aritmética;

Máx = valor máximo; e

Méd+DP = média mais desvio padrão. 
A simulação permitiu verificar a diferença entre as temperaturas do ar da cavidade durante o ano em relação ao meio externo para a fachada dupla na face norte do modelo simulado. A radiação incidente na camada externa da fachada dupla aumenta a temperatura do ar da cavidade, o que justifica esses valores. Os resultados obtidos indicam coerência com o fenômeno físico que envolve as camadas da fachada dupla. $\mathrm{O}$ aumento da temperatura do ar da cavidade proporciona uma diminuição de sua densidade, ativando, assim, sua circulação. Dessa forma, a ventilação natural pela cavidade da fachada dupla pode ser positiva ao ambiente ao provocar remoção de calor pela ventilação em períodos quentes ou ao aumentar os ganhos de calor nos momentos mais frios, dependendo da posição e área das aberturas nas camadas da fachada.

A radiação incidente na fachada e os ganhos térmicos pela janela do ambiente interno foram também analisados para os casos 2 e 3 no dia de projeto de verão (Figura 8 ) e no dia de projeto de inverno $^{4}$ (Figura 9). Na maior parte do dia de projeto de verão, os ganhos de calor no ambiente, advindos da janela, são menores para o caso com fachada dupla. O pico de ganhos térmicos que incluem os efeitos da radiação e da condução do caso $2\left(93,4 \mathrm{~W} / \mathrm{m}^{2}\right)$ é $25 \%$ menor em relação ao modelo sem fachada dupla $\left(123,7 \mathrm{~W} / \mathrm{m}^{2}\right)$ e $70 \%$ menor em relação à radiação incidente $(318,0$ $\mathrm{W} / \mathrm{m}^{2}$ ), às $12 \mathrm{~h}$. Cabe citar que nesse dia a nebulosidade presente e a altura solar mais elevada limitam a incidência da radiação solar na fachada.

Figura 7 - Temperaturas mínimas, médias e máximas das médias diárias de bulbo seco do ar externo e do ar da cavidade

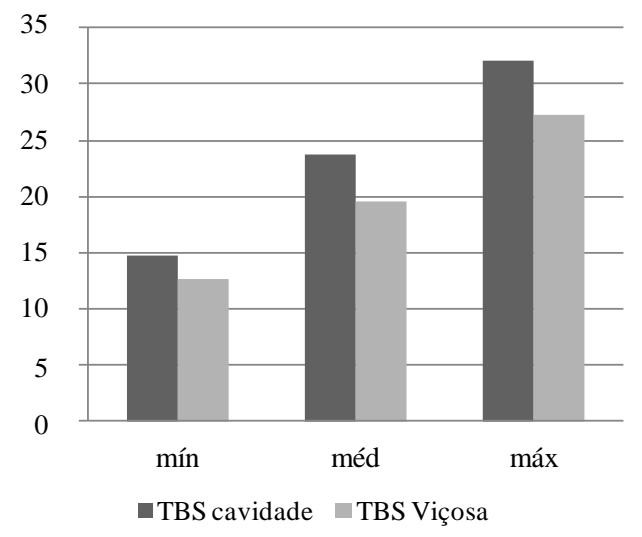

Figura 8 - Radiação solar incidente na fachada e ganho de calor no ambiente através da janela, no dia 3 de março, para janelas fechadas

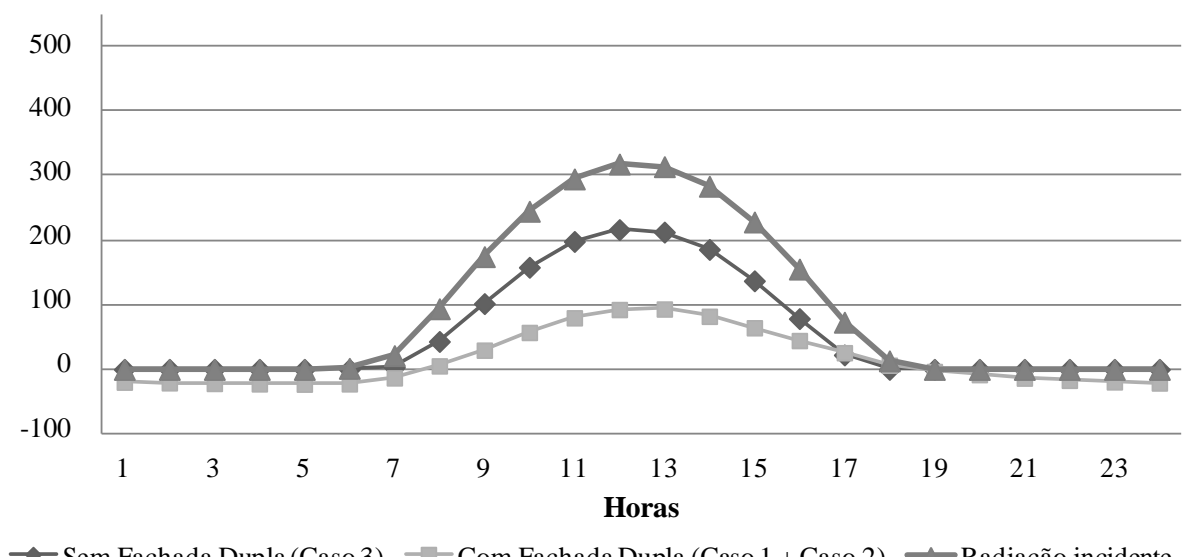

130 Barbosa, S. A.; Tibúrcio, T. M. de S.; Carlo, J. C.; Guimarães, I. B. B. 
Figura 9 - Radiação solar incidente na fachada e ganho de calor no ambiente através da janela, no dia 6 de julho, para janelas fechadas

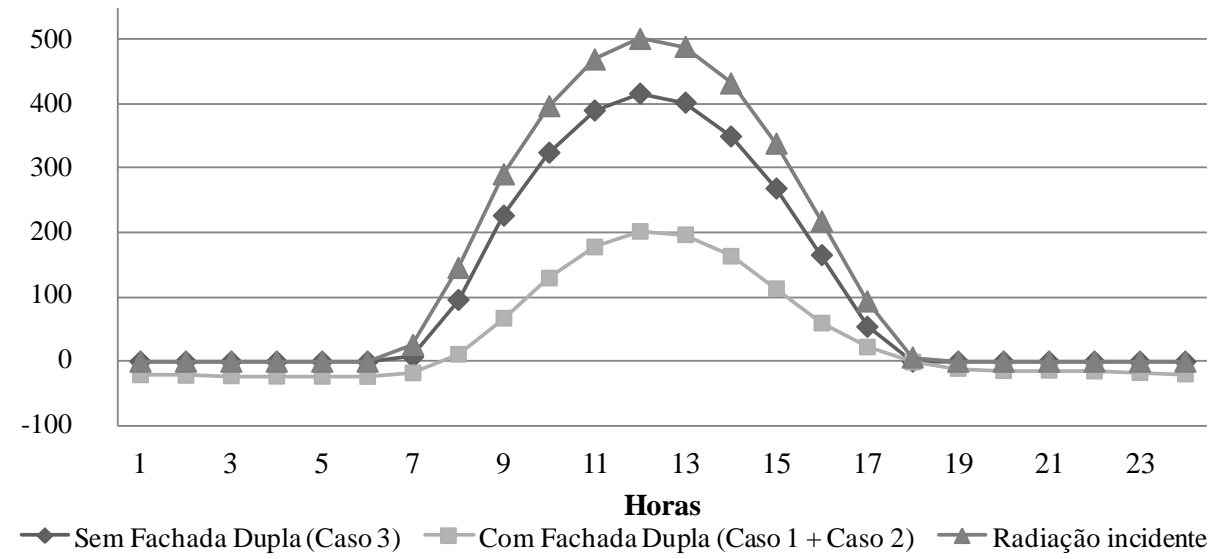

Para o dia de projeto de inverno, o ambiente com fachada dupla recebe, durante todo o dia, menos calor que o caso-base. A maior diferença entre os ganhos de calor dos casos com e sem fachada dupla ocorre às $12 \mathrm{~h}$, em que o caso sem fachada dupla recebe $416 \mathrm{~W} / \mathrm{m}^{2}$ e o caso com fachada dupla recebe $202 \mathrm{~W} / \mathrm{m}^{2}$, ou seja, $51 \%$ menos. Nesse mesmo momento, a radiação incidente na fachada norte é de $501 \mathrm{~W} / \mathrm{m}^{2}$.

É possível perceber que a fachada dupla limita a entrada de calor no ambiente, quando comparada à fachada convencional, o que é benéfico no período de verão. Para o período do inverno, é possível promover o armazenamento dos ganhos de calor adquiridos durante o dia na cavidade por meio do fechamento de seu topo. Assim, será possível elevar a temperatura do ambiente interno, mantendo seu desempenho favorável para o clima.

Para avaliar o desempenho dos casos estudados no ambiente interno, as temperaturas operativas foram verificadas, conforme mostrado nas Figuras $10 \mathrm{e}$ 11.

A partir da análise da Figura 10, é possível observar que a oscilação de temperatura operativa no caso com fachada dupla $\left(25-31^{\circ} \mathrm{C}\right)$ é menor do que no caso sem fachada dupla $\left(20-34{ }^{\circ} \mathrm{C}\right)$. No período da manhã (entre $6 \mathrm{~h}$ e $11 \mathrm{~h}$ ), as temperaturas operativas estão maiores no caso com fachada dupla. No período da tarde (das $12 \mathrm{~h}$ às $18 \mathrm{~h}$ ), essa condição se inverte, e o caso com fachada convencional apresenta temperaturas operativas horárias maiores que o modelo com fachada dupla.

Análise semelhante pode ser feita a partir da Figura 11, em que há menor oscilação da temperatura operativa do ambiente interno no caso com fachada dupla e maior no caso-base. No dia de projeto de inverno, a máxima passou de $26{ }^{\circ} \mathrm{C}$ para $23{ }^{\circ} \mathrm{C}$, e a mínima passou de $13{ }^{\circ} \mathrm{C}$ para $15^{\circ} \mathrm{C}$, do caso-base para o caso com fachada dupla respectivamente.

Assim, a fachada dupla funcionou como um amortecedor da temperatura do ambiente, promovendo maior estabilidade ao clima interno ao longo do dia. O caso-base, por outro lado, está mais vulnerável às variações das condições externas. Entretanto, esta pesquisa considera apenas a influência da trocas convectivas e condutivas provenientes dos efeitos da radiação solar entre as camadas da fachada. Na realidade, é possível que haja maiores trocas do ambiente interno com o meio externo, com o restabelecimento dos efeitos do vento.

\section{Conclusão}

$\mathrm{O}$ artigo apresentou um método de modelagem e comparação de resultados da simulação de um modelo de ambiente com fachada dupla, usando o programa de simulação computacional EnergyPlus. O método avaliou o desempenho térmico de um ambiente com fachada dupla em relação aos ganhos térmicos relativos à transmissão da radiação solar através das superfícies transparentes da fachada. A vantagem no uso desse procedimento refere-se à obtenção de resultados considerando as mudanças nas distribuições de temperatura nas camadas da fachada ao longo do tempo no ano completo. Essa é uma vantagem em relação às simulações que utilizam diretamente o CFD que não consideram as variações anuais das condições de contorno. 
Figura 10 - Temperatura operativa do ambiente interno, no dia 3 de março, para janelas fechadas

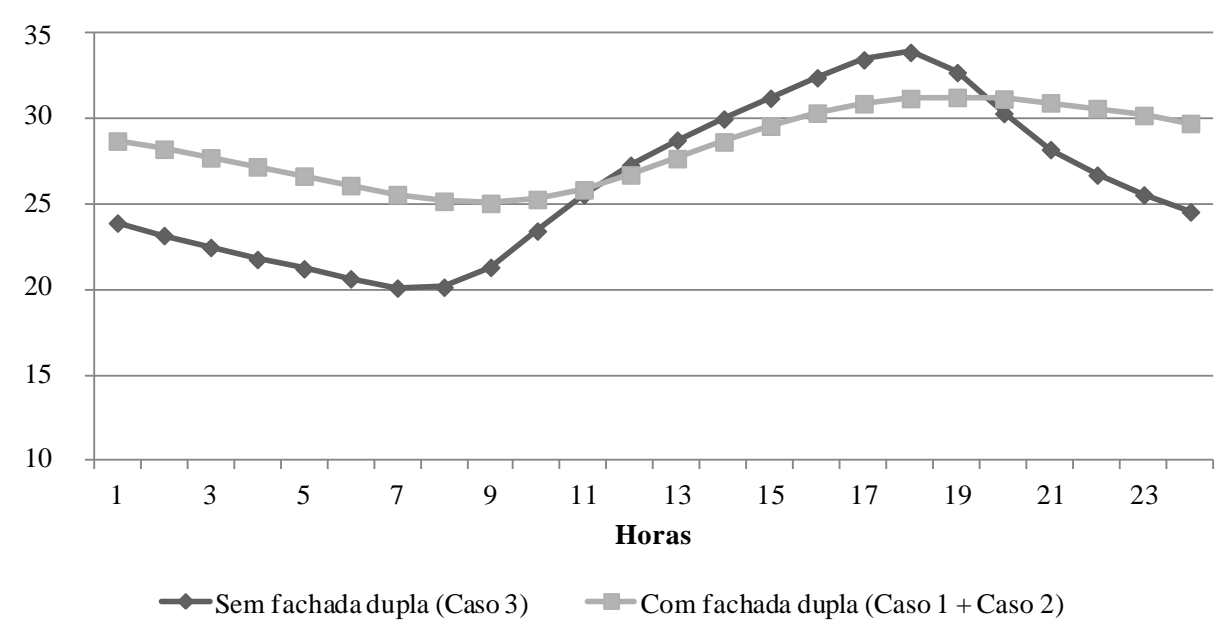

Figura 11 - Temperatura operativa do ambiente interno, no dia 6 de julho, para janelas fechadas

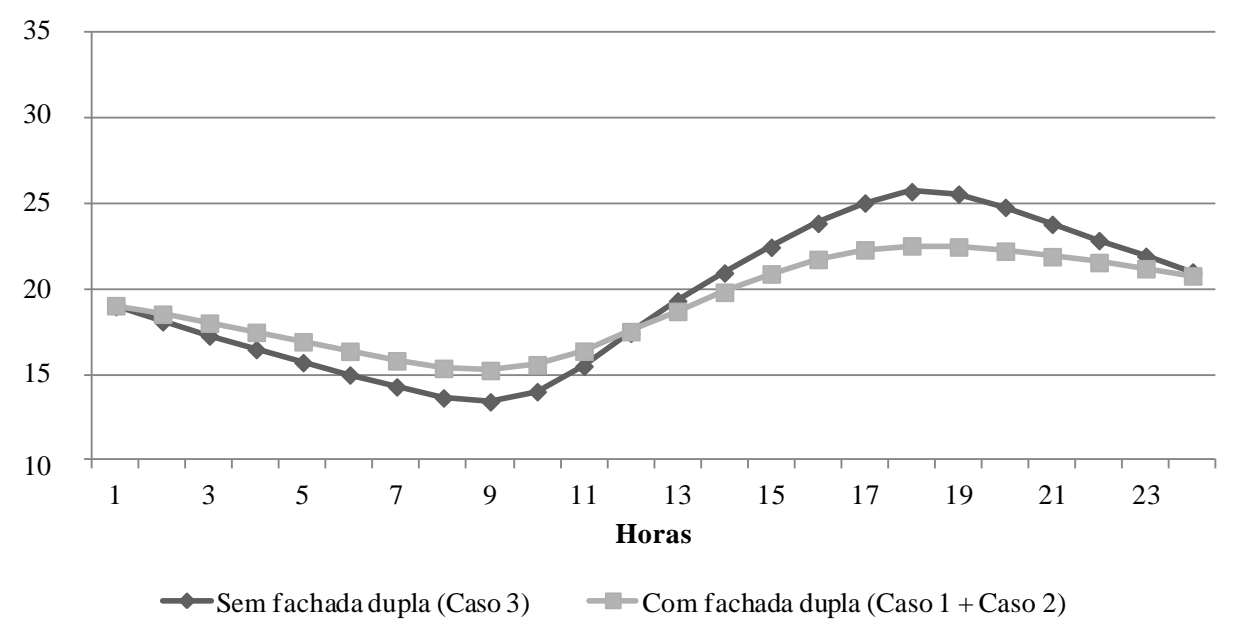

A limitação do procedimento é mostrada por meio das diferenças de temperaturas superficiais da face externa da janela nos casos 1 e 2. Essas diferenças podem ser causadas pelo efeito convectivo da chaminé térmica simulada no caso 1 , e não no caso 2, que foi definido com as condições do microclima da cavidade intermediária da fachada dupla. Assim, o caso 2, que não possui participação das trocas convectivas, apresenta temperaturas superficiais mais estáveis. Contudo, tendo em vista o número de dados analisados (8.760), as diferenças encontradas foram consideradas aceitáveis para uma análise de tendências de desempenho, já que em $90 \%$ das horas do ano os casos apresentaram diferenças de até $2{ }^{\circ} \mathrm{C}$.

As temperaturas médias diárias obtidas para o ar presente na cavidade da fachada dupla são em média de $4,2{ }^{\circ} \mathrm{C}$ maiores que o ar do exterior. A radiação incidente provoca a elevação de temperatura do ar na zona da cavidade, indicando que os resultados obtidos estão coerentes com o fenômeno físico que envolve as camadas da fachada dupla.

A oscilação da temperatura operativa do ambiente interno no caso com fachada dupla foi menor nos dias de projeto de verão e inverno. O ambiente com fachada dupla apresentou temperaturas entre $25^{\circ} \mathrm{C}$ e $31{ }^{\circ} \mathrm{C}$ pra o dia de projeto de verão, enquanto o caso-base oscilou entre $20^{\circ} \mathrm{C}$ e $34^{\circ} \mathrm{C}$. No dia de projeto de inverno, a variação de temperatura para o ambiente com fachada dupla ficou entre $15^{\circ} \mathrm{C}$ e $23{ }^{\circ} \mathrm{C}$, e o caso com fachada convencional, entre $13{ }^{\circ} \mathrm{C}$ e $26^{\circ} \mathrm{C}$. Assim, o caso sem fachada dupla está mais vulnerável às oscilações das condições externas do que o caso com fachada dupla. Contudo, é preciso considerar que, como o efeito do vento foi eliminado, sabe-se que na realidade haverá maiores trocas do ambiente com o meio externo. Além disso, as trocas convectivas devido à chaminé térmica podem ser capazes de retirar calor do ambiente, 
melhorando seu desempenho térmico nos períodos quentes. Esses fatores demandam mais investigações em relação ao desempenho de fachadas duplas, incluindo os efeitos do escoamento de ar pela cavidade e pelo ambiente interno.

O trabalho contribui com as investigações sobre simulação e avaliação dos efeitos das trocas radiantes nas camadas de fachadas duplas usando a ferramenta EnergyPlus. Esse método pode contribuir para uma escolha mais adequada da tipologia, comparando casos por meio da simulação de diferentes materiais, dimensionamentos e formas das camadas da fachada dupla. Cabe ainda fazer a mesma avaliação para outras orientações solares e para diferentes condições climáticas.

\section{Referências}

BALDINELLI, G. Double Skin Facades For Warm Climate Regions: analysis of a solution with an integrated movable shading system. Building and Environment, Oxford, v. 44, n. 6, p. 11071118, 2009.

CRAWLEY, D. B. et al. EnergyPlus: an update. In: SIMBUILD 2004, Boulder, 2004.

Proceedings... Boler, 2004.

DING, W.; HASEMI, Y.; YAMADA, T. Natural Ventilation Performance of a Double-Skin Façade With a Solar Chimney. Energy and Buildings, Oxford, v. 37, p. 411-418, 2005.

DUFFIE, J. A.; BECKAMN, W. A. Solar Engineering of Thermal Processes. $2^{\text {nd }}$ ed. New York: John Wiley \& Sons Inc., 1991.

EICKER, U. et al. Façades and Summer Performance of Buildings. Energy and Buildings, Oxford, v. 40, p. 600-611, 2008.

GAVAN, V. et al. Double-Skin Façade Exhaustive Simulation Throughout Combined Thermal and Daylight Modelling: application to optimal control. In: CONFERENCE ON PASSIVE AND LOW ENERGY ARCHITECTURE, 25., Dublin, 2008. Proceedings... Dublin, 2008.

GRATIA, E.; HERDE, A. de. The Most Efficient Position of Shading Devices in a Double-Skin Façade. Energy and Building, Oxford, v. 39, p. 364-373, 2007.
GUIMARÃES, Í. B. B.; CARLO, J. C. Caracterização Bioclimática da Cidade de Viçosa, MG. In: ENCONTRO NACIONAL DE CONFORTO NO AMBIENTE CONSTRUÍDO, 11.; ENCONTRO LATINO AMERICANO DE CONFORTO NO AMBIENTE CONSTRUIIDO, 7., Búzios, 2011. Anais... Búzios, 2011.

HENSEN, J. L.M. On Building Performance Simulation in a Changing Environment. In: BUILDING PERFORMANCE SIMULATION FOR DESIGN AND OPERATION, 2008. Proceedings... 2008.

HENSEN, J. L. M. LAMBERTS, R. Introduction to Building Performance Simulation. In: HENSEN, J. L. M.; LAMBERTS, R (Orgs.). Building Performance Simulation For Design and Operation. New York: Spon Press, 2011. cap.1, p. 1-14.

KIM, D.-W.; PARK, C.-S. Difficulties and Limitations in Performance Simulation of a Double Skin Façade With EnergyPlus. Energy and Buildings, Oxford, v. 43, p. 3635-3645, 2011.

MANZ, H.; FRANK, Th. Thermal Simulation of Buildings With Double-Skin Façades. Energy and Buildings, Oxford, v. 37, p. 1114-1121, 2005.

ORDENES, M. et al. Metodologia Utilizada na Elaboração da Biblioteca de Materiais e Componentes Construtivos Brasileiros Para Simulações no Visualdoe-3.1. Florianópolis, 2003.

PAPPAS, A.; ZHAI, Z. Numerical Investigation on Thermal Performance and Correlations of Double Skin Façade With Buoyancy-Driven Airflow. Energy and Buildings, Oxford, v. 40, p. 466-475, 2008.

RODRIGUES, J. M. et al. Efeitos Locais e de Larga Escala na Dinâmica Climática do Município de Viçosa - Minas Gerais. Sociedade \& Natureza, v. 22, n. 3, p. 593-610, 2010.

SREBRIC, J. Ventilation Performance Prediction. In: HENSEN, J. L. M.; LAMBERTS, R. (Orgs.). Building Performance Simulation For Design and Operation, New York: Spon Press, 2011. cap. 6, p. 143-179.

VERSAGE, R. de S. Ventilação Natural e Desempenho Térmico de Edifícios Verticais Multifamiliares em Campo Grande, MS. 2009. 96 f. Dissertação (Mestrado em Arquitetura e Urbanismo) - Universidade Federal de Santa Catarina, Florianópolis, 2009.

WONG, P.C.; PRASAD, D.; BEHNIA, M. A New Type of Double-Skin Façade Configuration for the Hot and Humid Climate. Energy and Buildings, Oxford, v. 40, p. 1941-1945, 2008. 


\section{Sabrina Andrade Barbosa}

Departamento de Arquitetura e Urbanismo | Universidade Federal de Viçosa | Av. P. H. Rolfs, s/n, Campus UFV | Viçosa - MG - Brasil | CEP 36570-000 | Tel.: (31) 3899-1959 | E-mail: s.andradebarbosa@gmail.com

\section{Túlio Márcio de Salles Tibúrcio}

Departamento de Arquitetura e Urbanismo | Universidade Federal de Viçosa | Tel.: (31) 3899-2759 Ramal 1963 | E-mail: tiburcio@ufv.br

Joyce Correna Carlo

Departamento de Arquitetura e Urbanismo | Universidade Federal de Viçosa | Tel.: (31) 3899-1982 | E-mail: joycecarlo@ufv.br

Ítalo Bruno Baleeiro Guimarães

Departamento de Arquitetura e Urbanismo | Universidade Federal de Viçosa | Tel.: (31) 3899-1959 | E-mail: italobbg@ymail.com

\section{Revista Ambiente Construído}

Associação Nacional de Tecnologia do Ambiente Construído

Av. Osvaldo Aranha, $99-3^{\circ}$ andar, Centro

Porto Alegre - RS - Brasil

CEP 90035-190

Telefone: +55 (51) 3308-4084

Fax: +55 (51) 3308-4054

www.seer.ufrgs.br/ambienteconstruido

E-mail: ambienteconstruido@ufrgs.br

134 Barbosa, S. A.; Tibúrcio, T. M. de S.; Carlo, J. C.; Guimarães, I. B. B. 